The «journey to the East» and the critical mysticism of the ethical proposal of Eugenio Trias

\title{
El «Viaje a oriente» y el misticismo crítico en la propuesta ética de Eugenio Trías
}

\author{
Carlos Segade Alonso
}

Universidad a Distancia de Madrid carlosemilio.segade@udima.es

DOI: https://doi.org/10.15366/bp.2020.24.004

Bajo Palabra. II Época. № 24. Pgs: 73-90

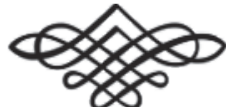


Recibido:18/03/2020

Aprobado: 28/07/2020

\section{Resumen}

En la filosofía de Eugenio Trías, la existencia, entendida como existencia ética, exige que el sujeto cumpla con el imperativo clásico de conocerse a sí mismo como condición del encuentro del sujeto consigo mismo. El objetivo de este estudio es dilucidar qué características tiene ese encuentro, por medio de una apelación a lo místico de raíz wittgensteniana, y cuál es la interpretación de «lo oriental» que lo hace posible.

Palabras clave: Eugenio Trías; filosofía del límite; existencia ética; misticismo; simbolo.

\section{Abstract}

In Eugenio Trías's Philosophy, existence, understood as an ethical existence, demands the subject to fulfil the classic imperative of knowing oneself, as a prime condition for the encounter of the subject with one's self. The objective of this study is to elucidate which characteristics may be found in that encounter, by means of an appeal to a mysticism of wittgenstenian origin, and how the concept of «oriental» is interpreted in order to make it possible.

Keywords: Eugenio Trias; philosophy of the limit; ethical existence; mysticism; symbol. 


\section{La ética en la filosofía del límiteł ser, razón y símbolo}

Eugenio Trías desarrolla su propuesta filosófica, la filosofía del límite, a lo largo de su amplia bibliografía. Con el fin de acotar el objeto de este estudio me centraré solo en tres de sus obras, aunque por razones expositivas también haga mención a otras donde se haga explícito el aparato conceptual de la filosofía del límite. Estas tres obras son: La edad del espiritu (1994) ${ }^{1,}$ Pensar la religión (1996) y Ética y condición humana (2000). En la primera, Trías investiga sobre el concepto de "espíritu" y desarrolla las categorías en las que este se ha manifestado en el tiempo; en la segunda, apunta hacia lo que se puede considerar como su propuesta de filosofía de la religión; un concepto de religión, por otro lado, que sería más semejante a un método de introspección personal para conciliar razón y simbolismo que a un sistema institucionalizado de postulados y ritos que exigen adhesión intelectual. En el último de mi selección, Trías fundamenta su propuesta ética, define el concepto de sujeto y explora la condición humana. Pero antes de entrar de lleno en la cuestión, repasaré cómo se llega desde la noción de límite a la reflexión ética.

La filosofía del límite se erige sobre tres pilares fundamentales: el ser del límite; la razón fronteriza y las formas simbólicas (o suplemento simbólico) ${ }^{2}$. Los tres están orgánicamente relacionados y apenas se pueden entender de manera independiente. El ser del límite parte de la definición clásica del ser tal y como aparece en Parménides y Aristóteles. La razón fronteriza es el logos que surge de la realidad fronteriza o condición fronteriza del ser humano. Las formas simbólicas son la prolongación de la razón fronteriza en referencia a cualquier cosa $(=x)$ que en su calidad de ser limítrofe no admite ser determinada mediante recursos racionales o conceptuales.

Estos tres conceptos forman, metafóricamente hablando, un triángulo, que Trías bautizó como "triángulo ontológico". Esta tríada da forma al núcleo de su filosofía, de manera que no puede faltar ninguno de ellos (ninguno de los vértices) si se quiere que el triángulo siga manteniendo su forma.

El ser es siempre ser del límite. Un límite tiene dos acepciones, una negativa y otra positiva. La más frecuente suele ser la que lo entiende como restricción, un borde que no se puede traspasar. Sin embargo, de manera positiva, el límite es el

\footnotetext{
${ }^{1}$ Estas son las fechas de publicación originales, que pueden no coincidir con las fechas de las ediciones manejadas en este trabajo.

2 Cfr. Trías, E., La razón fronteriza, Destino, Barcelona, 1999, pp. 18-20.
} 
equivalente al concepto de limes del Imperio Romano, el espacio que es susceptible de ser ocupado y habitado. Hablar de los límites de algo (del Imperio, por ejemplo) es tanto referirse a la franja última donde ese algo acaba, como todo el espacio que queda circundado por ese límite. En el límite, su aspecto negativo estaría figuradamente referido hacia fuera y el positivo hacia dentro. Lo que sí hay que advertir es que este espacio que conforma el límite existe de manera relativa, es decir, lo es en referencia a otro espacio que lo delimita.

Sobre esta idea Trías construye el resto del armazón conceptual de su filosofía. El límite está definido por tres espacios, que él llama "cercos»: el «cerco del aparecer», el "cerco hermético»y, en medio de ellos, el "cerco fronterizo». Estos cercos corresponden respectivamente a la realidad físico-natural, lo desconocido o arcano, y a un espacio de intersección entre ambos, que sería el fronterizo, al que me referiré más abajo. ${ }^{3}$

Es importante tener claro, para luego entender la ética triasiana y el lugar que ocupan el símbolo y el espíritu, que el ser es siempre ser del límite, es un habitante del cerco del aparecer, por ser precisamente parte de la realidad física y natural. Hay una relación de pertenencia con respecto del cerco del aparecer, pero el límite lo es «en referencia al» cerco hermético. El cerco del aparecer define la existencia mediante el límite, pero este no separa al Ser y al Ente, sino al Ser y la Nada. El límite da sentido tanto al cerco del aparecer como al hermético. Por eso el sujeto humano es un ser limítrofe, surge en el cerco del aparecer, pero es también fronterizo, existe en la frontera entre ambos cercos. El sujeto humano es consciente de su condición fronteriza, de encontrarse entre el Ser y la Nada, y ahí es, precisamente, en el cerco de la existencia, donde solo es posible la condición humana.

La manera en la que el sujeto se acerca a la realidad, a eso que se le "aparece", es a través de juicios. Estos los ordena la razón (fronteriza) en categorías, con el fin de comprender el mundo. Esta categorización es la que permite iniciar un proceso de reflexión o auto-reflexión crítica.

En la filosofía de Trías esta distribución de categorías es de vital importancia, ya que es el fundamento de su metodología analítica, que tiene un marcado carácter estructural, aunque esté combinada con un enfoque fenomenológico.

Las categorías son siete, ordenadas de manera lineal y progresiva, de tal manera que cada una de ellas presuponga la existencia de la siguiente y se explique por la anterior. Son las siguientes $\left.{ }^{4}: 1\right)$ la matriz: fundamento matricial, la Naturaleza;

\footnotetext{
${ }^{3}$ Gráficamente, Trías describió los cercos dibujando dos circunferencias sobrepuestas, una para el cerco del aparecer y otra para el hermético, cuyo espacio de intersección se correspondería con el cerco fronterizo (cfr. Trías E., Ciudad sobre ciudad. Arte religión y ética en el cambio de milenio, Destino, Barcelona, 2001: pp. 98-115).

${ }^{4}$ Las categorías se recogen en muchos de sus libros, y son el fundamento de La edad del espíritu. Sin embargo, en El hilo de la verdad se explican de nuevo de manera resumida y será esta referencia la que usaré en estos párrafos.
} 
2) la existencia: Mundo; 3) el sujeto: el límite; 4) el logos; 5) la razón crítica; 6) el suplemento simbólico: lo místico; 7) el ser del límite. Trías las explica agrupa de dos en dos, dejando la séptima como la integradora de todas las anteriores.

Las dos primeras se necesitan, la Naturaleza y la existencia, pero en orden inverso. En el momento en que se experimenta y se es consciente de la segunda, entonces es cuando la Naturaleza, que representa el origen y lo matricial, se aparece y se hace evidente. La existencia se entiende como algo diferente de la matriz que la hace posible. Esta existencia es el mundo que, a su vez, hace visible el límite. Por eso, lo que es en el mundo no es solo un ser, sino que es un ser "incardinado en el límite" 5

Esto lleva al segundo par de categorías, porque ese ser del límite es el sujeto. Mientras que en la anterior categoría no había diferenciación entre sujeto y objeto, era todo ser del límite, y se suspendía la diferenciación entre el límite y la nada, es el hecho de ser consciente de la nada, la negación de la existencia, la que eleva a esta a un status fronterizo, entre la existencia y su negación. Es la experiencia de la existencia limítrofe la que transforma al ser en sujeto fronterizo. El existente, el habitante de la frontera, por medio de la inteligencia (que es la que tiene acceso al logos y al significado del mundo), pasa a ser sujeto fronterizo y libre de determinarse en el límite; de esta forma, comenzaría su proceso de personalización, toda vez, como veremos más abajo, que curse la invitación de la proposición ética a ser como sí mismo.

Esta tercera categoría explica la siguiente: el logos. El objetivo del logos es explicar el mundo como una realidad con un sentido y con un significado. El sujeto fronterizo, consciente de su existencia vulnerable, sabe que es el mundo el que le dota de sentido, ya que es en el mundo. No solo es un ser arrojado en el mundo desde su matriz natural originaria, sino que ese modo de ser en el mundo es el propio del sujeto fronterizo. Es la aceptación del límite la que abre la posibilidad de que el logos actúe y se active. El logos no es el origen del límite sino que es por medio del reconocimiento del límite y la consiguiente libertad de aceptación de la proposición ética por las que "el sujeto se alza a la comprensión; a la inteligencia y la palabra" 6 .

Las siguientes tres categorías son las que construyen el triángulo ontológico que comentaba arriba ${ }^{7}$. La quinta categoría es la razón fronteriza, que tiene naturaleza crítica e incita al sujeto a la auto-reflexión. Es la más propiamente filosófica, ya que tiene como objeto el conocimiento de los mecanismos que hacen posible el recono-

\footnotetext{
${ }^{5}$ Cfr. Trías, E., El hilo de la verdad, Galaxia-Gutenberg, Barcelona, 2014, p. 77.

${ }^{6}$ Cfr. Trías, E., op. cit., p. 80.

7 Trías clasifica como "espontáneas" a las cuatro primeras categorías. Al sujeto se le dan, le vienen dadas por su propia condición de sujeto; sin embargo, a las tres restantes las denomina "reflexivas", porque el sujeto tiene que hacer un ejercicio de reflexión para poder averiguar las claves de su significado.
} 
cimiento de las categorías espontáneas. Dicho de otro modo, la razón fronteriza es la encargada de proveer un aparato crítico al logos para que sea capaz de reconocer su condición limítrofe, o sea, le muestra, le hace evidente el límite a la inteligencia.

La sexta categoría surge cuando el logos es llevado a tal extremo de contemplación y comprensión del límite que descubre el "tránsito del mundo hacia lo arcano" ${ }^{8}$. Es el reconocimiento de que el existir tiene un final; el sentido es terminal. Ese momento es el que llama Trías "prueba mística". Es entonces cuando al logos se le lleva al extremo de su racionalidad para que trate de aquello que no está en la existencia, que es, como veíamos, su ámbito natural. Esta categoría hace visible el suplemento simbólico, el símbolo, que tiene su referencia en el cerco hermético, lo que está más allá del límite, que es otro modo de expresar que esta categoría revela en el mundo algo que está escondido (en el cerco hermético). Mientras tanto, la razón fronteriza se interroga sobre qué es legítimo preguntarse sobre el cerco hermético. Por eso ambas van juntas, una revela el hecho de que hay algo que pone fin a nuestra existencia, que se presenta como lo que hace posible hablar de un límite de la existencia, y la otra se pregunta hasta qué punto y cómo podemos hablar de ello.

$\mathrm{Al}$ producirse esta intersección entre la razón fronteriza y la revelación simbólica se pone de manifiesto el ser tal y como es; se despliega el ser como ser del límite, de tal manera que todas las categorías anteriores convergen en una sola, la séptima y última. Esto es como decir que el habitante del límite descubre su condición iluminado por la razón, que le ayuda a encarnar, como persona (no solo como sujeto o individuo) lo que le informa o le da a conocer la inteligencia, que no es otra cosa que la verdad sobre su condición de ser del límite. Este conocimiento personifica, pero también lo harán la producción estética y la experiencia espiritual.

Una vez llegados a este punto, con las categorías definidas y delimitadas, pasaré a describir los efectos de la proposición ética y sus consecuencias, para posteriormente poder entender la conexión que tiene con el misticismo y el pensamiento oriental.

Decía arriba que la razón fronteriza es la que muestra a la persona la conciencia de estar en el mundo y ser libre, es decir, regirse por un principio ético. Este principio es, en realidad, un imperativo, que cabe calificar también de categórico. Es muy fácil de enunciar debido a sus resonancias clásicas y Trías lo trae a colación prácticamente en todas sus obras porque es uno de los pilares básicos de su pensamiento: "obra de tal manera que la máxima que determina tu conducta, y tu acción, se ajuste a tu propia condición de habitante de la frontera" ${ }^{9}$, o, lo que es lo mismo, pero

\footnotetext{
${ }^{8}$ Cfr. Trías E., op. cit., p. 81.

9 Cfr. Trías, E., Etica y condición humana, Península, Barcelona, 2000, p. 47.
} 
expresado en términos de la filosofía del límite: "sé fronterizo; acierta a comportarte como lo que eres, límite y frontera" ${ }^{10}$.

$\mathrm{Al}$ explicar el bloque de las primeras categorías decía que la persona se sitúa entre una condición animal (matricial y naturalista) y una condición divina (simbólica), que habría que interpretar más en el sentido de deseo de ser o parecer dioses. Sin embargo, el hecho de ser humano es una condición que le viene dada al habitante del límite; un ser humano no la puede evadir y, por tanto, esta se entiende como un imperativo. Por consiguiente, el "ser lo que somos" enuncia un imperativo ético. Por su parte, el ser humano puede responder a este imperativo bien aceptando su condición o bien rechazándola. Este ejercicio sería el fundamento de la libertad humana.

La actitud de rechazo puede derivar en los dos sentidos, coincidiendo con los extremos de los que nos informan las categorías, es decir, una opción sería retrotraerse a su origen animal, reduciendo su condición a mera physis, y la otra, en dirección opuesta, concentrando la mirada en el cerco hermético hasta asimilarse a él, convirtiendo la herencia simbólica en Razón Absoluta, que dominaría su praxis, haciendo creer al ser humano que está investido de naturaleza divina (hermética).

La respuesta propia del ser limítrofe, la de mantenerse en el equilibrio entre ambas, se ve recompensada con la "buena vida", que no es otra cosa que el resultado del ejercicio continuado de la libertad de optar por un equilibrio entre ambos polos. Es el ideal ético.

De esto se deduce que, para Eugenio Trías, la libertad es inherente a la acción humana, pero no como resultado de un mero acto volitivo sino desde la perspectiva de querer dar respuesta a un imperativo al que se ve interpelado, una invitación de una voz arcana, hermética, que primitivamente se identificaba con los dioses, el creador o el padre.

El hecho de que se entienda este principio ético como un imperativo también despeja dudas sobre su posible relativización. En la ética triasiana no todo vale. Hay un límite negativo a la respuesta, que es la condición fronteriza; uno no puede ir más allá de ese límite. Por otro lado, como todos los seres humanos están interpelados por el imperativo, se trata de una ética de carácter universal, pero que requiere respuestas individuales. Consecuentemente, una persona no puede responder a la interpelación en el lugar de otro; ese otro se vería sin capacidad de respuesta personalizadora a su propio imperativo. Por tanto, una persona que traspasa el límite, por ejemplo, arrogándose un papel de intérprete o conocedor del cerco hermético

\footnotetext{
${ }^{10}$ Cfr. Trías, E., op. cit., p. 49. A este imperativo, o proposición ética, Trías lo bautizó de varias maneras, como imperativo pindárico, por su similitud con el "llega a ser lo que eres" de Píndaro, o imperativo délfico, por aquel clásico mandato de los oráculos, "conócete a ti mismo".
} 
estaría contraviniendo un principio ético básico, ya que cada uno es responsable de su propia respuesta al imperativo.

Una vez expuesto cómo se constituye el sistema categorial y su relación con el imperativo ético, se exponen a continuación las razones que aduce Trías para enriquecer la auto-reflexión propia de la razón fronteriza con la mirada oriental.

\section{La razón del «viaje a Oriente»}

La propuesta de Eugenio Trías pasa por "abrir, pues, las puertas de Asia e introducir un difícil diálogo hermenéutico con la sabiduría oriental" ${ }^{11}$.

Como se ha mostrado arriba, en una última instancia, la condición humana empuja a la razón fronteriza a un proceso de auto-reflexión. El problema surge cuando ese proceso se ve solo condicionado por el logos occidental, es decir, la razón occidental que se manifiesta de tres maneras distintas pero interrelacionadas: la razón tecno-científica (intuida por Heidegger), la burocrático-desencantada (en Max Weber) y la capitalista (descrita por Marx) ${ }^{12}$. Ninguna de ellas, sin embargo, logra un proceso de síntesis suficiente como para aunar lo racional con lo simbólico. El problema es que, si se quiere analizar lo simbólico desde la razón occidental, se acaba haciendo una interpretación desde alguno de esos tres posicionamientos. Sin embargo, la razón para que esto suceda es más remota.

Nos dice Trías que con la identificación entre ser, pensar y decir, y con las primeras referencias al logos de Parménides, comienza el distanciamiento con el pensamiento oriental, que, no obstante, se mantiene abierto a lo simbólico. Aunque los neoplatónicos o los gnósticos, mediante la recuperación de ciertos elementos orientales, trataron de hacer posible la fusión de ambas tradiciones, al final la razón occidental terminó por imponerse. Esto supondría una total quiebra del marco epistemológico en Occidente, que solo se podría entender como apelación a la trascendencia, mientras que en Oriente los simbólico representaría la cotidianeidad. Por eso, Trías propone ir más lejos de lo que fue Heidegger en su vuelta a Grecia y seguir más allá hasta alcanzar Oriente ${ }^{13}$.

11 Cfr. Trías, E., Pensar la religión, Galaxia-Gutenberg, Barcelona, 2015, p. 57.

12 Cfr. Trías E., op. cit., pp. 53-55.

${ }^{13}$ El filósofo Peter Kingsley también rastreó influencias primitivas desde Platón: "De Platón, y a través del mito del Fedón, podemos viajar hacia atrás en el tiempo hasta Empédocles” (cfr. Kingsley, P., Filosofía antigua, misterios y magia, Atalanta, Girona, 2017: p. 165). Kingsley dedujo así el pensamiento pitagórico, el órfico y las influencias caldeas en el pensamiento griego clásico, además de las egipcias o incluso algunas de origen más remoto, como por ejemplo la creencia en la reencarnación. Desde un punto de vista metodológico sería plenamente factible mirar hacia Oriente desde los fundamentos del pensamiento occidental. 
Este viaje «de vuelta» a Oriente, sin embargo, no debe leerse como una ruptura con Occidente, sino más bien como un diálogo. Lo que pretende Trías no es exiliarse de Occidente y renunciar al racionalismo para abrazar los modos orientales, sino iniciar un diálogo de la filosofía occidental con la sabiduría oriental de tal manera que esta aporte su familiaridad con el Absoluto, con lo que tiene de raíz matricial y de visión no-dual de la Realidad. El Absoluto oriental no se identifica con la Razón, sino que tiene una raíz matricial (en el sentido en que la palabra se entiende en Trías). En Oriente el ser se concibe como trascendente con respecto al pensamiento y a su realización lingüística, un indefinido que se resiste a ser pensado, mientras que en Occidente el ser es siempre ser del pensamiento.

Para Trías, esa apertura es el punto final de su filosofía de la religión, pero el principio de su propuesta religiosa. Es necesario entender que, para Eugenio Trías, lo "religioso" no implica, como dije arriba, la adhesión a ritos o a postulados dogmáticos o a unas creencias obligatorias en personajes más o menos míticos, sino que apunta hacia una actitud abierta a lo que él llama sagrado, misterioso o arcano, entendido este como un mapa espiritual que ofrece una ruta hacia lo simbólico; de ahí la denominación de cerco hermético, donde se sitúa el objeto de lo religioso, que tiene naturaleza exclusivamente simbólica y que representa el repositorio del patrimonio de los eternamente muertos, el saber y experiencia humana de los que nos precedieron, y que nos enfrenta, a su vez, al límite de nuestra existencia. Esto resuena como el comentario de Wittgenstein a la obra de Frazer ${ }^{14}$ : "En nuestro lenguaje está depositada toda una mitología”.

En la interpretación triasiana ${ }^{15}$, la experiencia religiosa evoluciona en tres grandes fases ${ }^{16}$. La primera de ellas hace referencia a un período inicial de atribución sagrada a lo natural, es la época de la magia, de la «Magna Diosa». Esta fase se ve rebasada por la irrupción del logos (correspondería a la segunda categoría que se veía en el epígrafe anterior) y por el comienzo del patriarcado religioso. Lo sagrado se «revela» por medio de la palabra, sus postulados se hacen ley, autoridad, y la Magna Diosa da paso a un padre poderoso, dueño, rey, guerrero y señor de los cielos y la tierra (Yahveh, Odín, Zeus), que impone su ley y dicta justicia, decidiendo qué es verdad y qué falsedad. Es un momento de reconocimiento y creación del cosmos, un tiempo en el que se amplía la visión de la naturaleza inmediata para descubrir e imponer leyes cósmicas, y se pone orden en todo lo creado.

\footnotetext{
${ }^{14}$ Cfr. Wittgenstein, L., Observaciones a "La rama dorada» de Frazer, Tecnos, Madrid, 2012, p. 69.

15 Cfr. Trías, E., Pensar la religión, op. cit., pp. 75-97.

${ }^{16}$ En el libro Pensar la religión, Trías habla de "principios», que en realidad son estados o fases de la evolución de la experiencia religiosa, y que pasan a denominarse "categorías» en La edad del espíritu. Cada una de estas fases estaría motivada por principios distintos: un principio matricial, un principio formal y eficiente, y un principio teleológico, que suscita o da pie a la idea de salvación o «rescate».
} 
Por último, una tercera fase (principio, categoría) es la del reconocimiento del mal en el mundo, de tal manera que tras la fase autoritaria patriarcal se desee volver al acogimiento de la Madre, al estado primigenio de inocencia, limpios de la experiencia del mal. Es la fase del Enviado, del Iluminado, del que rescata a los hombres para devolverles la libertad primigenia. Este principio conecta el origen con el final, define el télos y da sentido a la existencia más allá de la mera subordinación a la ley cósmica. Descubre el origen del mal (el sufrimiento, el dolor, el «pecado») y lo redime, lo borra, y retorna al principio matricial. En realidad, es una vuelta al cerco hermético, pero es el núcleo constituyente de cualquier religión moderna.

Para Trías, cualquier experiencia religiosa integra estos tres principios, el matricial, el formal y el teleológico, y es precisamente esta superposición de principios lo que provoca las tensiones propias de las religiones, es decir, la tensión entre lo formal, el seguimiento de «la ley» y la espontaneidad que precisa la búsqueda de sentido, de liberación. El modo en que se impone un principio a los otros tres también definiría a cada una de las religiones, e incluso cada una de ellas en el transcurrir del tiempo, ya que pueden darse fases de mayor prevalencia de un principio que de otro, o intentos de equilibrio de un principio (por ejemplo, el matricial con su énfasis en figuras femeninas cuasi-divinas) con el resto.

En consonancia con el análisis categorial visto arriba, los principios de la experiencia religiosa irían en paralelo a las cuatro primeras. Correspondería al tercer grupo de categorías ver brotar la propuesta religiosa de Trías, la «religión del espíritu» ${ }^{17}$. Lo cierto es que no hay que entender esta como una nueva religión, en el sentido de culto, o una religión que nazca de la filosofía, sino de una experiencia de la presencia del cerco hermético que pueda ser compartida por todo el mundo desde la razón. Es fundamental comprender que esta propuesta trata de conjugar la razón occidental con la experiencia del ser trascendente oriental, tal y como se ha visto en este epígrafe, porque de lo contrario, no se podría entender la conjugación entre lo místico y la razón occidental.

De cómo se articula esta religión del espíritu con la ética y el suplemento simbólico trata el siguiente epígrafe.

\section{Mística, símbolo y espíritu en la razón fronteriza}

El eSPÍRITU SE DEFINE COMO "la síntesis entre símbolo y razón" o, lo que es lo mismo, "la razón revelada, finalmente reconciliada con el universo simbólico" ${ }^{18}$.

${ }^{17}$ Cfr. Trías E., op. cit. p. 65.

${ }^{18}$ Cfr. Trías, E., La edad del espíritu, Debolsillo, Barcelona, 2014, p. 538. 
Es, por tanto, un intento de superación de una fase caracterizada por el carácter antinómico de la razón y el simbolismo. La séptima categoría corresponde a esta superación, pero el diálogo, el proceso por el cual la razón es consciente del símbolo, es propio de la sexta categoría, la que corresponde a la filosofía contemporánea, desde Nietzsche a Wittgenstein pasando por Freud.

Es precisamente de Wittgenstein ${ }^{19}$ del que parte Trías para explicar su visión de lo místico. La comprensión del límite, de la razón fronteriza, es lo propio de la sexta categoría, pero de tal manera que "la visión del mundo sub specie aeterni [sic] es su visión como-todo-limitado. El sentimiento del mundo como todo limitado es lo místico" ${ }^{20}$. E igualmente, "lo inexpresable, ciertamente, existe. Se muestra, es lo místico" ${ }^{21}$. Trías no solo se ayuda en su sexta categoría de esta afirmación del Tractatus, sino que hace suyo el punto final del mismo ${ }^{22}$ : "De lo que no se puede hablar hay que callar". De esa imposibilidad de crear proposiciones con sentido en la contemplación del símbolo nace la necesidad de lo místico, como actitud ética que no puede dejar de ser estética, simbólica ${ }^{23}$. Como explica Sádaba ${ }^{24}$, la conexión entre una y otra viene de la contemplación sub specie aeternitatis del objeto, en el caso de la obra de arte (estética), y del mundo, en el caso de la «buena vida» (o ética).

Este posicionamiento coincide con el de Underhill ${ }^{25}$, expuesto en su influyente tratado sobre la mística. Si la búsqueda de la Realidad es solo intelectual puede darse que o bien se acabe por aceptar lo real del mundo como pura representación, o bien que se elabore una teoría, necesariamente simbólica, que intente explicar esa Realidad, o bien se caiga en el total escepticismo que, a pesar de su estructura lógica, impida seguir preguntándose por el carácter simbólico de la Realidad. Ante ese bloqueo al que aboca el trabajo en solitario del logos, el místico reivindica la pura experiencia, rechazando la posibilidad de que el conocimiento se adquiera solo por medios sensoriales, la pura intelección o el "contenido de la conciencia normal" 26. Con lenguaje religioso, a propósito de su estudio comparativo entre Sankara y Eckhart, también Rudolf Otto ${ }^{27}$ detecta esta predisposición común a ambas tradicio-

19 Cfr. Wittgenstein L., Tractatus logico-philosophicus, Alianza Editorial, Madrid, 2003. A partir de aquí se referencian solo los párrafos de la obra en vez de la página.

20 Íbidem, 6.45.

21 Íbidem, 6.522 .

22 Íbidem, 7.

23 Íbidem, 6.421.

${ }^{24}$ Cfr. Sádaba, J., Lenguaje, magia y metafísica. (El otro Wittgenstein). Libertarias-Prodhufi, Madrid, 1992, pp. 29-34.

25 Cfr. Underhill, E., La mistica. Estudio de la naturaleza y desarrollo de la conciencia espiritual, Trotta, Madrid, 2006, p. 28.

26 Íbidem, p. 37.

27 Cfr. Otto, R., Mistica de Oriente y Occidente. Sankara y Eckhart, Trotta, Madrid, 2014, p. 52. 
nes, oriental y occidental, cuando afirma que "Dios/Atman [el Objeto, la Realidad] es antes un silencio que un discurso".

Según Javier Sádaba ${ }^{28}$, las interpretaciones de lo místico se pueden reducir a dos, la de querer alcanzar un objeto de carácter sobrenatural y otra cuyo objeto es el mundo mismo; la primera sería la visión occidental y la segunda la oriental; las resume diciendo que "en este sentido, lo místico de lo que nos habla Eugenio Trías podría interpretarse como nuestra relación con el Universo entero".

Cuanto más teológica sea la interpretación de mística que se maneje, más se tiende a asimilarla a un proceso orientado a la aprehensión de un objeto dentro de los límites de una confesión religiosa ${ }^{29}$, cuyo objetivo sea el acceso privilegiado a lo divino como prueba de perfección. También lo místico teísta se puede interpretar como fenómeno extremo de veracidad del hecho religioso ${ }^{30}$, o como el impulso que equilibra la dimensión social, racional e introspectiva de la religión ${ }^{31}$. Esta experiencia introspectiva también se puede entender como experiencia humana común y, por tanto, hacer de la mística un puente para el diálogo ${ }^{32}$ de filosofías distantes entre sí. Si se abre al diálogo con Oriente, la mística se podría concebir como un intento de vivir una experiencia integral que trascienda una realidad que se da a conocer como lenguaje simbólico, artístico o poético ${ }^{33}$.

Sin embargo, cuanto menos teísta es la interpretación de la mística, más se entiende como un proceso de goce de la experiencia pura sin mediación lingüística, por lo que puede ayudar a solucionar la escisión entre la realidad y el discurso simbólico (el dualismo con el que tiene que enfrentarse la filosofía) ${ }^{34}$.

${ }^{28}$ Cfr. VV. AA., Sobre Eugenio Trías, Galaxia-Gutenberg, Barcelona, 2018, p. 71.

29 Cfr. González de Cardedal, O., Cristianismo y mística, Trotta, Madrid, 2015, p. 30: "solo hay legitimidad para hablar de mística cuando esta entronca con la historia positiva de Dios que se inicia con Abrahám, cuando se remite a la persona de Jesús, cuando nace y crece en la comunión eclesial".

${ }^{30}$ Cfr. Martín Velasco, J., Mistica y humanismo, PPC, Boadilla del Monte, 2008, p. 7: "la clave para la verdad y la autenticidad de la religión”.

31 Íbidem, p. 109.

32 Esta es la propuesta de Darío Carrero en López-Baralt, L. y Cruz Sotomayor, B., Repensando la experiencia mistica desde la insulas extrañas, Trotta, Madrid, 2013, pp. 333-340. La mística de Carrero tiene un sesgo político y liberacionista, pero se pretende que sea vía de diálogo de posturas encontradas, desde el posmodernismo de Vattimo, pasando por el pragmatismo de Rorty, hasta el liberacionismo de Dussel.

33 Cfr. Panikkar, R., Obras completas I. Mistica y espiritualidad. 1. Mistica, plenitud de vida, Herder, Barcelona, 2015, pp. 209-225. Panikkar considera la mística como el puente entre Occidente y Oriente, tanto en la filosofía como en la teología natural. La mística la concibe como la vía para experimentar la Realidad que se manifiesta simbólicamente, pero que se puede aprehender trascendiendo la forma del símbolo y la carga de su significado.

34 Para una visión de la mística desde el agnosticismo y en este mismo sentido, véase Pániker, S., Filosofía y mistica. Una lectura de los griegos, Kairós, Barcelona, 2003, pp. 10-16. La filosofía de Salvador Pániker fusiona por un lado la tradición pragmatista y escéptica, desde Hume, y elementos de la tradición advaita. Para Pániker la mística es la culminación de un proceso de racionalidad crítica (íbidem, pp. 120-121); parte de la prerracionalidad para posteriormente alcanzar la racionalidad y hasta a alcanzar la racionalidad crítica, cuyo final es el ascenso (o descenso, según se mire) a lo místico. Es un proceso que va de lo acrítico a lo hipercrítico, siendo lo místico el 
Por su parte, Eugenio Trías entiende la mística como un encuentro, y este será también el principio sobre el que gira su ética: un encuentro o desencuentro de un sujeto en relación a sí mismo ${ }^{35}$. Como decía anteriormente, es el sujeto el que se ve impelido al imperativo ético délfico. Toda su ética implica la reflexión sobre las consecuencias que produce el hecho de que el sujeto siga o no siga el imperativo de conocerse a sí mismo, de ser uno mismo.

Trías entiende ese conocimiento como un encuentro personal del sujeto con lo que él llama su daimon (o sí mismo), y ese encuentro tiene carácter de acontecimiento (ético). El daímon representa en la ética del límite el elemento que, según sea ese encuentro con el sujeto, supondrá una orientación o una desorientación para este. El daimon condiciona al sujeto su lugar en el mundo y el modo en que está en él; el encuentro con el daimon es un conocer que es a la vez conocerse. Para Trías, este encuentro es también un acontecimiento simbólico. Haciendo uso una vez más del significado etimológico de la palabra "símbolo", el sujeto y el sí mismo responderían a cada una de las dos mitades, unidas mediante el encuentro, movidas por una fuerza o un deseo (que proviene del eros) de conocer el sentido que les proporciona ese encuentro. Por eso, ese acontecimiento simbólico es un acontecimiento también filosófico, ya que en su esencia es un deseo de conocimiento. Aquí, Trías interpreta al daímon como maestro interior que guía al sujeto, como un discípulo, por la senda del conocimiento ${ }^{36}$.

Pero sería un error pensar que esa parte simbólica con la que se encuentra el sujeto tiene un significado o que representa algo. El símbolo es la propia existencia, el acontecer existencial, no la representación de algo que existe más allá del cerco del aparecer. No es un ente divino, ni de ningún otro tipo. El encuentro es la elevación del sujeto, que se encuentra en el cerco del aparecer, a un acontecimiento espiritual consigo mismo. El espíritu, lejos de tener conexiones extra humanas, es la fuerza que es capaz de provocar en el sujeto el encuentro con el sí mismo. Al acuerdo entre el sujeto y su daímon es lo que se podría calificar de "verdad".

En el epígrafe introductorio se explicaba el sistema categorial de la filosofía del límite. Es importante aquí no perderlo de vista, porque las categorías describen al ser del límite. Las cuatro primeras categorías (matriz, existencia, limes y logos) tienen carácter fenomenológico; las dos siguientes (razón fronteriza, símbolo) son hermenéuticas; la séptima (ser del límite) es la categoría fronteriza ${ }^{37}$. Las categorías

resultado del cuestionamiento de la propia razón crítica. Es la superación de las clasificaciones, demarcaciones y escisiones de la realidad creadas por los actos culturales humanos. Es la búsqueda de la no-dualidad, tras el dualismo provocado entre la realidad y el logos.

35 Cfr. Trías, E., Pensar la religión, op. cit., pp. 198-202.

36 Cfr. Trías, E., op. cit. p. 203.

37 Cfr. Trías, E., La razón fronteriza, op. cit., p. 319. 
son modos en los que se da a conocer el ser del límite, que es inteligible: "un logos que es, a la vez, racional y simbólico, o filosófico y artístico-religioso. Es decir, espiritual" ${ }^{38}$. La que corresponde al hecho místico es la sexta categoría (símbolo), que ofrece "la posibilidad de remontar hasta el último confín inteligible, allí donde el sentido se abisma en la transcendencia del misterio, o del cerco hermético" ${ }^{39}$. Lo "espiritual", lo que proviene del "espíritu", no es una manifestación de una divinidad, sino la convergencia entre la razón (fronteriza) y lo simbólico (cuyo locus es el cerco hermético), que es lo misterioso, lo arcano, lo que está fuera de lo humanamente controlable, que no puede ser dicho pero sí puede actuar como referente negativo del ser del límite y sombra del logos, y que la religión y las artes han tratado de explicar. Por eso, la "edad del espíritu", un ideal de la razón, no apela a una época de predominio de la religión, sino a esta concepción del diálogo entre la razón y el símbolo. De hecho, así se expresa Trías en la conclusión final del libro La edad del espiritu: "Propongo, pues, en este libro, una edad del espíritu como horizonte de nuestra existencia (personal y colectiva), en la que la razón y simbolismo puedan articularse o conjuntarse. En esa conjunción se formaría lo que aquí llamo espíritu. Y este sería entonces el logos que daría forma al ser del límite (o al habitante de la frontera) ${ }^{40}$.

La razón fronteriza, la quinta categoría, es la inteligencia humana que se sabe en el mundo pero que, a la vez, es consciente de estar rodeada de misterio o de enigmas, que se pueden experimentar pero no expresar, al estilo de Wittgenstein, quien llamó "lo místico" a todo ese conjunto de cosas que son un límite a la propia expresión. Para Trías, eso "místico" no puede ni debe condicionar al sujeto habitante de la frontera, ya que todo lo que se diga sobre ello está más allá de la razón, por lo que la religiosidad que pueda resultar de una actitud mística pasa por la inteligencia (razón fronteriza) y la libertad responsable ${ }^{41}$, pero no por la sacralización o la institucionalización.

Tal concepción de lo místico podría llevarnos a pensar que Trías está en la misma sintonía de algunas religiones que proponen un "despertar" a una nueva realidad, a un "estado elevado" de conciencia que ha sido caracterizado y descrito en innumerables tradiciones religiosas y culturales. En el zen se habla de satori, en las tradiciones yóguicas de samadhi, que pueden coincidir con el Tao absoluto del taoísmo, o el fana del sufismo ${ }^{42}$. Todos estos estados, incluyendo otras definiciones

\footnotetext{
38 Íbidem, p. 409.

39 Íbidem, p. 410.

${ }^{40}$ Cfr. Trías, E., La edad del espiritu, op. cit., p. 542.

${ }^{41}$ Cfr. Trías, E., La razón fronteriza, op. cit. p. 430.

${ }^{42}$ Cfr. Román, M. T., La exploración de la conciencia en Oriente y Occidente, Kairós, Barcelona, 2017, pp. 136-137.
} 
un tanto pintorescas, como la "experiencia plateau" de Maslow, hacen referencia a una experiencia inefable pero que no es forzadamente religiosa, porque no exige la existencia de la divinidad ni una solución teísta a los problemas propios de la condición humana. Algunos de estos "movimientos filosófico-religiosos de extraordinaria lucidez, como el budismo", como llegaría a afirmar Trías ${ }^{43}$, hacen uso de esas "metáforas" para referirse a eso que no se puede nombrar, pero para Trías, ese encuentro, el acontecimiento simbólico, no se da entre el ser humano y una Realidad en la que se integra, como una comprensión final de la no-dualidad, sino entre el ser humano y la realidad sobre sí mismo (el encuentro con el daimon), que le hace consciente de su condición limítrofe y que le conecta con el resto del universo.

\section{Conclusión: caracterización de lo místico en la filosofía del límite}

El acercamiento a Oriente de Eugenio Trías no viene de un deseo de experimentar con nuevas experiencias religiosas, o como rechazo a la cultura capitalista o hedonista. Su mirada oriental es resultado de la búsqueda de un origen, no con un interés nostálgico o arcaizante, sino con el interés de aquel que sabe que, en el camino de su evolución, la filosofía se fue dejando parte de lo que era su esencia, esa antigua invitación a la introspección que se verbaliza en el "conócete a ti mismo". Ese viaje, como se ha visto, no toma atajos, sino que desanda lo recorrido hasta llegar a ese punto de encuentro originario donde se produjo el hiato entre el pensamiento oriental y el occidental. Trías, por tanto, no evita ni desdeña la obra filosófica occidental, sino que es a través de ella como llega a Oriente; pero tampoco hace suyas ni reivindica las prácticas que siguen las religiones orientales, sino que las somete a la misma crítica metodológica que aporta su sistema de categorías.

Lo místico, por tanto, va más allá de una actitud religiosa sublime o de una actitud proclive a buscar objetos espirituales más allá del ser personal. En la filosofía del límite, lo místico es condición de posibilidad para el ser del límite, insertado en el carácter simbólico de la sexta categoría; representa la apertura al misterio, donde ilumina a la inteligencia y hace posible el arte, pero no se arroga el derecho de dictar la libertad humana ni supone una revelación de misterios de los que no puede hablar. Lo místico es, por tanto, condición de lo humano.

Por consiguiente, con el fin de sistematizar lo místico en la filosofía del límite, se proponen las siguientes características distintivas de un concepto que, como pasa a

${ }^{43}$ Cfr. Trías, E., La razón fronteriza, op. cit., p. 405. 
menudo con el aparato conceptual de la filosofía de Trías, adopta diferentes rasgos semánticos según se vaya avanzando en el análisis fenomenológico de la condición humana:

(1) Lo místico es crítico. En Trías lo místico es crítico en sí mismo, en tanto que enjuicia y actúa como sombra del logos, está presente siempre, y no solo como final o cumbre de un proceso de análisis crítico. Lo místico no es la inteligencia, ni tampoco la razón fronteriza, pero se hace visible a esta para poder completar el ser del límite. Lo místico limita entonces a la razón y al uso del lenguaje y, por tanto, somete a juicio de forma continua las proposiciones que pretenden arrogarse el contenido simbólico (del cerco hermético). Por ello, lo místico invita a la duda sobre la veracidad de las prácticas basadas en lo arcano, en lo propio del cerco hermético, y permite al ser humano activar su libertad como tal ser humano, sin deudas hacia proposiciones creadas a partir de intuiciones de lo que constituye el cerco hermético.

(2) Lo místico es personalizador. El ser humano, a decir de Trías, no es individuo ni sujeto, sino persona. Esto quiere decir que el sujeto, invitado a conocerse a sí mismo, se convierte en consciente de su diferencia con respecto a otros seres, se aleja de lo matricial y se convierte en ser humano consciente, ser del límite. Pero la consciencia de abandonar la raíz matricial y de saber que hay una nada que lo limita, no le hace habitante de esa nada. Que el ser humano sea consciente del cerco hermético no le hace habitarlo, sino todo lo contrario, sigue habitando el cerco del aparecer, pero consciente del cerco hermético, en ese otro locus que Trías denomina el cerco fronterizo. En otras palabras, el ser del límite sabe que no es animal, pero que no puede jugar a ser dios.

(3) Lo místico es universal. Igual que el acontecimiento ético es universal, lo místico también lo es. La llamada del imperativo ético es propia de la condición humana, igual que la respuesta que conlleva obedecer al mandato de conocerse a uno mismo, de ser uno mismo. Pero lo mismo que la raíz matricial es universal, en virtud de la cual todo ser humano se sabe habitante del cerco del aparecer, o sea, de este mundo físico, y lo entiende y lo expresa por medio del logos, el ser fronterizo se da cuenta de que el cerco hermético supone para él un límite, y un límite del que no puede hablar. Por tanto, cualquier ser humano consciente de su condición es también consciente de lo místico, lo simbólico, pero por la vía de la experiencia, no del logos. 
Estas tres características creo que engloban lo que tiene que decir la filosofía del límite en cuanto a la definición de lo místico. Lo interesante es que esta concepción que tiene Eugenio Trías del misterio simbólico es muy compatible, por sí misma, con el pensamiento oriental, en el que la nada y la realidad no-dual juegan un papel muy relevante.

La filosofía de Trías propone seguir explorando lo místico haciendo posible que posemos nuestra mirada en dirección a Oriente, a través de nuestras propias fuentes occidentales, con el fin de recuperar para nosotros una sabiduría que no dependa solo de nuestra concepción del ser-pensar-decir. En esa relación entre Oriente y Occidente, la filosofía del límite ambiciona estar en el lugar de la conjunción, sirviendo de puerta giratoria en ambos sentidos. 


\section{ReFERENCIAS Bibliográficas}

González de Cardedal, O., Cristianismo y mistica, Trotta, Madrid, 2015.

Kingsley, P., Filosofía antigua, misterios y magia, Atalanta, Girona, 2017.

López-Baralt, L. y Cruz Sotomayor, B. (Eds.), Repensando la experiencia mistica desde las insulas extrañas, Trotta, Madrid, 2013.

Martín Velasco, J., Mistica y humanismo, PPC, Boadilla del Monte, 2008.

Otto, R., Mistica de Oriente y Occidente. Sankara y Eckhart, Trotta, Madrid, 2014.

Pániker, S., Filosofía y mistica. Una lectura de los griegos, Kairós, Barcelona, 2003.

Panikkar, R., Obras completas I. Mistica y espiritualidad. 1. Mistica, plenitud de vida, Herder, Barcelona, 2015.

Román, M. T., La exploración de la conciencia en Oriente y Occidente, Kairós, Barcelona, 2017.

Sádaba, J., Lenguaje, magia y metafísica. (El otro Wittgenstein), Libertarias/Prodhufi, Madrid, 1992.

Trías, E., La razón fronteriza, Destino, Barcelona, 1999.

Trías, E., Ética y condición humana, Península, Barcelona, 2000.

Trías, E., Ciudad sobre ciudad. Arte, religión y ética en el cambio de milenio, Destino, Barcelona, 2001.

Trías, E., La edad del espíritu, Debolsillo, Barcelona, 2014.

Trías, E., El hilo de la verdad, Galaxia-Gutenberg, Barcelona, 2014.

Trías, E., Pensar la religión, Galaxia-Gutenberg, Barcelona, 2015.

Underhill, E., La mistica. Estudio de la naturaleza y desarrollo de la conciencia espiritual, Trotta, Madrid, 2006.

VV.AA., Sobre Eugenio Trías, Galaxia-Gutenberg, Barcelona, 2018.

Wittgenstein, L., Tractatus logico-philosophicus, Alianza Editorial, Madrid, 2003.

Wittgenstein, L., Observaciones a «La rama dorada» de Frazer, Tecnos, Madrid, 2012.

DOI: https://doi.org/10.15366/bp.2020.24.004

Bajo Palabra. II Época. No 24. Pgs: 73-90 